\title{
PRODUÇÃO DE BRIQUETES PARA QUEIMA UTILIZANDO FINOS DA PRODUÇÃO DE CARVÃO VEGETAL E GLICERINA
}

\author{
G. S. RODRIGUES, L. J. HELMER, M. C. M. DEVENS, P. R. F. FONSECA e G. SIMONELLI* \\ Universidade Federal da Bahia - UFBA \\ gsimonelli@ufba.br
}

Submetido 12/05/2016 - Aceito em22/02/2017

DOI: $10.15628 /$ holos.2017.4559

\section{RESUMO}

Este trabalho teve como objetivo avaliar a viabilidade técnica da produção de briquetes a partir de finos de carvão vegetal e de glicerina bruta, para a geração de energia. A importância deste trabalho está relacionada ao desequilíbrio entre oferta e demanda da glicerina no mercado e à grande geração de resíduos de finos de carvão nas indústrias carvoeiras. Briquetes são materiais compactados que possuem formato definido e alto poder energético na queima. Foram produzidos briquetes de três composições de glicerina $(10,15$ e $20 \%)$, três composições de amido de milho como aglutinante $(5,10$ e $15 \%)$ e duas pressões de compactação (283 e $425 \mathrm{kgf.cm}{ }^{-2}$ ). Os briquetes foram confeccionados numa prensa hidráulica, conformados em um molde cilíndrico com $67 \mathrm{~mm}$ de diâmetro. A
\end{abstract}

qualidade dos briquetes foi avaliada por meio de análises de resistência ao impacto, teor de cinzas e poder calorífico. Em relação à resistência ao impacto, em diferentes composições, os briquetes produzidos foram capazes de suportar 3 quedas. Em termos de teor de cinzas, os briquetes com composição de $65 \%$ de carvão, $20 \%$ de glicerina e $15 \%$ de aglutinante apresentaram os melhores resultados. E para o poder calorífico, os melhores resultados foram obtidos na composição de $70 \%$ de carvão, $20 \%$ de glicerina e $10 \%$ de aglutinante. Assim, entre esses dois, o último foi considerado o melhor briquete, pois, além de apresentar valores semelhantes de teor de cinzas, possui melhor poder calorífico e utiliza maior quantidade de finos de carvão.

\section{BRIQUETTES PRODUCTION OF BURNING USING THIN OF CHARCOAL PRODUCTION AND GLYCERINE}

\begin{abstract}
This study aimed to assess the technical feasibility of producing briquettes from charcoal fines and crude glycerin, for power generation. The importance of this work is related to the imbalance between supply and demand of glycerin in the market and the great generation of coal fines waste in bunkers industries. Briquettes are compressed materials that have defined shape and high energy power in the burning. Three glycerin compositions were produced briquettes $(10,15$ and $20 \%)$, three compositions corn starch as binder (5, 10 and $15 \%$ ) and two compaction pressures (283 and $425 \mathrm{kgf} . \mathrm{cm}^{-2}$ ). The briquettes were made in a hydraulic press, formed into a cylindrical mold of $67 \mathrm{~mm}$
\end{abstract}

diameter. The quality of the briquettes was assessed by analysis of impact resistance, ash content and calorific value. Regarding impact strength, in different compositions, briquettes produced were able to withstand 3 falls. In terms of ash content in the briquettes composition of $65 \%$ carbon, $20 \%$ glycerin and $15 \%$ binder showed the best results. And for the heating power, the best results were obtained in the composition of $70 \%$ carbon, $20 \%$ glycerin and $10 \%$ binder. So between these two, the latter was considered the best briquette because, besides having similar values of ash content, heating value and has better uses larger amount of coal fines.

KEYWORDS: Biomass, Briquetting, Ash content, Calorific value. 


\section{INTRODUÇÃO}

Continuamente são gerados resíduos em virtude da produção industrial de bens de consumo. Atualmente, a destinação adequada para os resíduos gerados nas indústrias tem se tornado uma questão importante, que resulta inclusive na busca de alternativas para aproveitar materiais. Nesse sentido, a briquetagem pode ser considerada uma opção de aproveitamento de resíduos com potencial energético, tornando-os matérias-primas de baixo custo para a geração de energia térmica.

A briquetagem é uma técnica na qual a biomassa é prensada formando blocos de forma e tamanhos definidos, denominados de briquetes. Na grande maioria, esses briquetes se apresentam no formato cilíndrico. É sabido que em média $1 \mathrm{~m}^{3}$ de briquete contém em torno de 5 vezes mais energia que $1 \mathrm{~m}^{3}$ de resíduo, pois proporciona uma estrutura favorável à queima. 0 briquete é uma conformação muito eficiente para concentrar a energia disponível na biomassa (CARVALHO; BRINCK, 2004).

Um resíduo muito significativo para a produção de briquetes advém das indústrias de carvão vegetal. Na produção do carvão vegetal ocorrem perdas de matéria-prima, ou seja, o produto se quebra gerando grande quantidade de finos de carvão, que se torna um resíduo, pois não possui interesse comercial. Sua produção anual é de aproximadamente 9 milhões de toneladas, o que confere à nação brasileira o primeiro lugar no ranking da produção dessa matéria-prima (MORAES, 2011). Esse insumo energético é amplamente utilizado nas indústrias (siderúrgica, de cerâmica, cimenteira, alimentícia) e no setor doméstico como carvão para churrasco.

Por outro lado, os impactos ambientais advindos da exploração de combustíveis fósseis, bem como, uma futura escassez das reservas destes combustíveis, têm alavancado pesquisas para buscar fontes alternativas de energia. Além disso, a política energética brasileira prevê o incentivo à utilização de fontes renováveis, o que tem aumentado a produção de biodiesel (MOTA; SILVA; GONÇALVES, 2009).

O biodiesel é uma fonte energética renovável que possui potencial para substituir total ou parcialmente o diesel. A produção do biodiesel gera um coproduto denominado glicerina, que por sua vez, é gerada em grandes quantidades. O despejo da glicerina não pode ser realizado em corpos hídricos, pois quando em contato com a água, dificulta a oxigenação de animais aquáticos. Além disso, seu preço no mercado brasileiro caiu consideravelmente desde o início da produção do biodiesel. Em razão desse fato, boa parte dos produtores de biodiesel prefere armazenar a glicerina produzida, esperando que os preços voltem a subir (MOTA; SILVA; GONÇALVES, 2009).

Com esta grande oferta de glicerina no mercado, estudos têm sido feitos para encontrar soluções que melhor aproveitem a glicerina. Cordoba (2011) estudou a combustão de glicerina bruta e desenvolveu um queimador próprio para ela, avaliando parâmetros operacionais da combustão. Além disso, Astals et al. (2010) estudaram a glicerina como um composto orgânico biodegradável que pode ser aplicado como um co-substrato no processo de digestão anaeróbica 
de estrume de porco. Anger et al. (2011) verificaram a conversão de glicerina num gás rico em hidrogênio de síntese, através do procedimento de reforma de água supercrítica. Sant'anna et al. (2011) estudaram a obtenção de briquetes a partir de resíduos agroindustriais como cascas de frutas, misturados com a glicerina bruta advinda do processo de biodiesel; posteriormente foram analisados os testes de poder calorífico e análise química imediata.

Considerando o possível potencial energético da fabricação de briquetes produzidos a partir da mistura de um subproduto (glicerina bruta) e de um resíduo (finos de carvão vegetal), este estudo pode ser considerado uma forma para solucionar um problema ambiental e trazer uma aplicação eficiente para estes materiais.

\section{REVISÃO BIBLIOGRÁFICA}

O briquete é um material que passa pelo processo de briquetagem. A briquetagem consiste na aglomeração de partículas finas por meio de pressão, com auxílio, ou não, de aglutinante. Como resultado da briquetagem obtém-se um produto compactado, de forma definida, com parâmetros físico-químicos adequados para a queima e de fácil armazenamento e transporte (CARVALHO; BRINCK, 2004).

O processo de briquetagem pode ser efetuado de duas maneiras distintas: com ou sem aglutinante. Para este último, devem-se levar em consideração as condições do material a ser briquetado, tais como umidade do material, capacidade de compressão das partículas, porosidade do briquete e tratamento térmico posterior à briquetagem (CARVALHO; BRINCK, 2004).

Vários trabalhos na literatura abordam briquetes produzidos a partir de diversas matériasprimas como bagaço de cana-de-açúcar (BASQUEROTTO, 2010), carvão vegetal e alcatrão de madeira (MELO, 2000), carvão vegetal e extrato de frutos (MORAES, 2011), resíduos lignocelulósicos (PROTÁSIO et al., 2012), lodo primário (PELISSARI; AMARAL; ESTEVES, 2012) e caroço de açaí, casca de cacau e serragem (RODRIGUES et al., 2002).

Segundo Melo (2000), antes da prensagem, é necessário que haja homogeneização dos componentes quando o briquete for composto por mais de um material, ou quando houver a adição de algum aglutinante. Isso favorecerá a obtenção de um produto final mais uniforme.

A aglomeração eficiente das partículas é muito importante na briquetagem. Melo (2000) afirma que os briquetes que apresentam melhor qualidade são os produzidos com partículas com granulometria de até $0,25 \mathrm{~mm}$. Porém, em razão da existência de uma ampla variedade de matérias-primas e aglutinantes, é difícil a determinação uma granulometria ideal para todas as situações.

Pelissari, Amaral e Esteves (2012) mostraram resultados que relacionam a pressão de compactação com a resistência ao impacto, em um briquete composto por lodo primário da produção de celulose e pó de serra. Os autores revelam que o aumento da pressão de compactação, proporcionou um aumento significativo na resistência ao impacto. Em pressões de compactação de 63, 126 e 253 kgf.cm ${ }^{-2}$, os briquetes produzidos suportaram 6, 10 e 12 quedas sem ruptura, respectivamente. 
Segundo Carvalho e Brinck (2004), os principais testes para a análise de qualidade de um briquete são a resistência ao impacto, o teor de cinzas e o poder calorífico.

$\mathrm{Na}$ literatura, encontram-se inúmeras aplicações para a briquetagem, porém, fica claro que a maior importância desse processo está relacionada ao aproveitamento de resíduos e outras matérias-primas, a fim de reestruturá-las em uma forma que possa ser utilizada para gerar energia térmica.

O briquete é utilizado para a queima em pizzarias, padarias, lareiras, caldeiras de termoelétrica, indústria de cerâmica vermelha, siderurgia, aquecedores, torradores e outros similares, pois seu poder calorífico é significativamente maior que o da lenha (MAGOSSI, 2007).

\section{MATERIAIS E MÉTODOS}

Para a realização desta metodologia, foi necessária a utilização dos finos de carvão vegetal, glicerina bruta e como aglutinante o amido de milho industrial não refinado.

Os finos de carvão foram coletados em uma carvoaria localizada no município de Linhares, Espírito Santo (ES) e foram armazenados em sacos plásticos.

Não foi possível conseguir glicerina bruta proveniente de processo de produção de biodiesel, pois o estado Espírito Santo não possui nenhuma fábrica de biodiesel ativa. Devido ao baixo valor de mercado da glicerina bruta, as empresas que comercializam esse produto geralmente vendem em quantidade mínima de cem toneladas, o que impossibilitou a aquisição deste produto em pequenas quantidades. Contudo, a glicerina bruta foi preparada em laboratório com base nos dados da literatura.

Como aglutinante, foi utilizado o amido de milho não refinado.

A análise granulométrica dos finos de carvão foi feita utilizando-se a sequência de peneiras de modelo Granutest, padrões ABNT de números 18, 20, 30, 40, 50, 60, 70, 80, 90 e 100, respectivamente.

Materiais estranhos como folhas e gravetos que poderiam prejudicar a formação dos briquetes foram removidos manualmente dos finos de carvão.

Os finos de carvão foram triturados no moinho de facas tipo Willey. Em seguida esse material foi armazenado em recipientes plásticos para evitar que a matéria-prima entrasse em contato com a umidade do ar.

A glicerina bruta foi preparada segundo formulação de Striugas et al. (2008), conforme Tabela 1. 
Tabela 1: Componentes básicos da glicerina bruta.

\begin{tabular}{ccc}
\hline Componentes & Unidade & Glicerina Comercial \\
\hline Glicerol $^{\text {Metanol }}{ }^{1}$ & $\%$ massa & 80 \\
Fosfato de sódio $^{2}$ & $\%$ massa & 0,5 \\
Ácidos Graxos Livres $^{2}$ & $\%$ massa & 9,0 \\
Água $^{\text {Água }}$ & $\%$ massa & 1,5 \\
\hline
\end{tabular}

Fonte: Adaptado de STRIUGAS et al. (2008).

${ }^{1} \mathrm{O}$ metanol (0,5\% em massa) não foi adicionado na produção da glicerina bruta, devido seu grau de toxicidade.

${ }^{2} \mathrm{O}$ ácido graxo livre foi substituído pelo óleo vegetal, a fim de simular a presença do mesmos.

Para o glicerol foi utilizada a glicerina comercial bi-destilada da marca Farmex e misturada com os demais componentes disponíveis no Laboratório de Química Orgânica das Faculdades Integradas de Aracruz (FAACZ).

$\mathrm{Na}$ etapa de mistura foram produzidos em triplicata nove tipos diferentes de briquetes (Tabela 2), variando a composição entre finos de carvão, glicerina e aglutinante (amido de milho). A porcentagem de cada componente foi definida a partir de pré-testes realizados em laboratório.

Tabela 2: Composição dos briquetes produzidos

\begin{tabular}{cccccccccc}
\hline Componente & & \multicolumn{1}{c}{ Briquetes } \\
\hline Amido & 1 & 2 & 3 & 4 & 5 & 6 & 7 & 8 & 9 \\
Glicerina & $5 \%$ & $5 \%$ & $5 \%$ & $10 \%$ & $10 \%$ & $10 \%$ & $15 \%$ & $15 \%$ & $15 \%$ \\
Carvão & $10 \%$ & $15 \%$ & $20 \%$ & $10 \%$ & $15 \%$ & $20 \%$ & $10 \%$ & $15 \%$ & $20 \%$ \\
\hline
\end{tabular}

Após a mistura das matérias-primas, as mesmas foram dispostas em um tubo de aço para definir o formato do briquete (molde), que foi de forma cilíndrica e com extremidade inferior fechada.

A mistura juntamente com o molde foi colocada na prensa hidráulica, modelo Schulz com capacidade máxima de 15 toneladas para a realização da prensagem. As cargas utilizadas no presente estudo foram 10 e 15 toneladas, ou seja, $238 \mathrm{kgf.cm}{ }^{-2}$ e $425 \mathrm{kgf.cm}$.

Com os briquetes produzidos avaliou-se a resistência ao impacto, o teor de cinzas e o poder calorífico.

As análises de resistência ao impacto foram realizadas no laboratório de hidráulica da FAACZ; o teste de teor de cinzas no laboratório de química do Instituto Federal do Espírito Santo (IFES) - campus Linhares; e o poder calorífico no Laboratório Central da FIBRIA, unidade de Aracruz.

Para os testes de resistência ao impacto foi utilizado o método proposto por Carvalho e Brinck (2004) para briquetes sem tratamento térmico. Neste procedimento, o briquete é abandonado de uma altura de $30 \mathrm{~cm}$ e colide com o solo. Para verificar a resistência ao impacto foram contadas as quedas suportadas até ocorrer a ruptura completa do briquete (PELISSARI; AMARAL; ESTEVES, 2012).

O teor de cinzas foi determinado mediante o procedimento proposto pela NBR 8289 de 1983 da ABNT. Primeiramente um grama da amostra de briquete foi triturado e seco. Em seguida 
a amostra foi adicionada a um cadinho de massa conhecida e posteriormente introduzido em um forno mufla modelo Vulcan 3-350PD à 700 C, por tempo de aproximadamente 6 horas. Após a queima, o cadinho foi levado a um dessecador para resfriamento e em seguida sua massa foi pesada (PELISSARI; AMARAL; ESTEVES, 2012). A obtenção de teor de cinzas se deu conforme a Equação (1).

$$
T_{c}=\frac{M_{r}-M_{c}}{M_{a}} \times 100
$$

Diminuiu-se a massa do cadinho com o resíduo da combustão, (Mr), da massa do cadinho vazio (Mc). Esse resultado foi dividido então pela massa da amostra, (Ma), e por último, multiplicado por 100, para que o teor de cinzas, (Tc), fosse expresso em porcentagem.

O poder calorífico foi determinando conforme estabelecido pela NBR-8633 de 1984 da ABNT. Um grama da amostra, previamente triturada e seca, foi posta em combustão em uma bomba calorimétrica IKA C4000. O poder calorífico foi medido pela energia térmica produzida na combustão e seu valor foi expresso em $\mathrm{kcal}_{\mathrm{kg}}{ }^{-1}$. Por fim, os valores de poder calorífico dos briquetes produzidos foram comparados com briquetes presentes na literatura.

\section{RESULTADOS E DISCUSSÕES}

Após a trituração do pó de carvão, realizou-se análise granulométrica. A distribuição granulométrica está representada abaixo (Tabela 3).

Tabela 3: Granulometria da amostra dos finos de carvão

\begin{tabular}{ccc}
\hline Mesh (\#) & Tamanho da partícula $(\mathbf{m m})$ & \% Retido \\
\hline 18 & 1,00 & 0 \\
$<20$ & $1,00-0,85$ & 4,54 \\
$20-30$ & $0,85-0,60$ & 9,95 \\
$30-40$ & $0,60-0,42$ & 19,37 \\
$40-50$ & $0,42-0,30$ & 16,73 \\
$50-60$ & $0,30-0,25$ & 11,69 \\
$60-80$ & $0,25-0,18$ & 20,50 \\
$80-100$ & $0,18-0,15$ & 8,48 \\
$>100$ & $<0,15$ & 8,75 \\
\hline
\end{tabular}

É possível através da Tabela 4, concluir que 62,27\% das partículas de pó de carvão estão dento da granulometria esperada, sendo considerado um percentual satisfatório, uma vez que os $37,73 \%$ restantes estão com tamanhos de partículas inferiores, o que reduz ainda mais a distância entre as partículas, que é o objetivo da etapa de trituração de acordo com Quirino e Brito (1991).

Os briquetes produzidos possuíram $67 \mathrm{~mm}$ de diâmetro e em média $55 \mathrm{~mm}$ de altura.

Para estimar a capacidade dos briquetes produzidos de suportar o estresse provocado pelos impactos gerados durante seu manejo, foi empregado o teste de resistência ao impacto. 
Estão dispostos na Figura 1 os resultados do teste de resistência dos briquetes produzidos para as duas pressões de compactação utilizadas no estudo.

\section{№ de quedas}

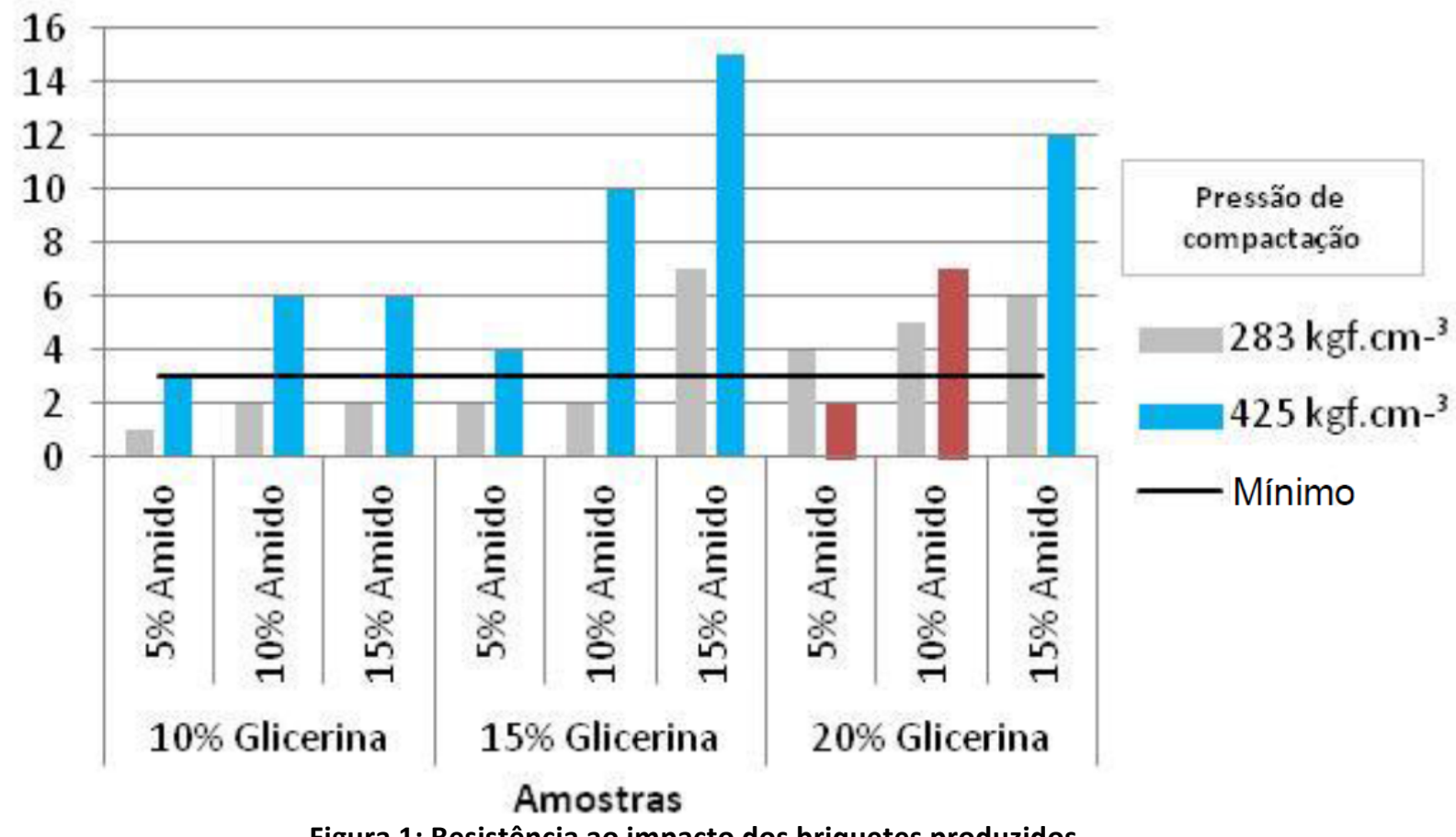

Figura 1: Resistência ao impacto dos briquetes produzidos.

A Figura 1 confirma que a maioria dos briquetes apresentaram resistência ao impacto satisfatória, comparando-se ao que foi definido por Carvalho e Brinck (2004) - que briquetes não curados devem suportar 3 quedas no mínimo para serem considerados resistentes, e para briquetes curados, no mínimo 10 quedas. Assim, houveram briquetes que excederam até mesmo a especificação para briquetes curados.

Observou-se também que houve uma relação entre a concentração do aglutinante e a quantidade de quedas suportadas. Notou-se que o aumento da concentração de aglutinante conferiu ao briquete uma estrutura mais rígida e, por consequência, uma maior resistência ao impacto. Isso era de se esperar, sendo que o aglutinante age como um material ligante (MELO, 2000; MORAES, 2011).

Em relação à glicerina, nota-se que alterada a composição de $10 \%$ para $15 \%$, houve um aumento geral na resistência de todos os briquetes nas duas pressões de compactação.

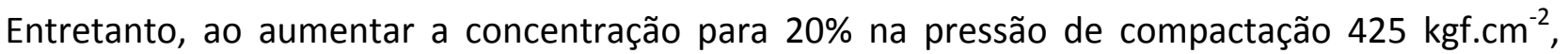
houve uma queda média na resistência dos briquetes. Isso pode ser explicado levando em consideração que, durante a compactação nessa pressão, os briquetes com $20 \%$ de glicerina nas composições de 5 e 10\% de amido, apresentaram vazamento. Então, para essa pressão e fração de glicerina, os briquetes com 5 e 10\% de amido não apresentam um resultado válido em número de quedas, pois a composição do briquete foi alterada pela perda de glicerina. Além do que, o próprio vazamento já mostra a impossibilidade da utilização dessas duas composições à pressão de $425 \mathrm{kgf.cm}{ }^{-2}$. 
Também percebeu-se que ao diminuir a pressão de compactação de $425 \mathrm{kgf.cm}{ }^{-2}$ para

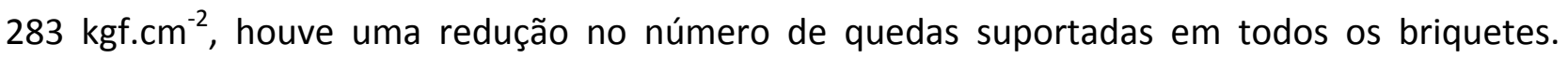
Apesar dessa diminuição, alguns briquetes suportaram 3 ou mais quedas, fato importante, levando em consideração que menores pressões demandam menos energia, reduzindo o custo de produção. Além disso, as composições que apresentaram vazamento na pressão de 425 kgf.cm ${ }^{-2}$, não tiveram esse problema a partir da aplicação da pressão mais baixa, gerando briquetes com resistência satisfatória (PELISSARI; AMARAL; ESTEVES, 2012).

A fim de obter a quantidade de matéria que resta após a queima do briquete, foi feita a análise do teor de cinzas.

Tem-se então, na Figura 2, os valores percentuais médios de cada amostra de briquete em diferentes composições. As barras em vermelho representam as composições em que houve vazamento de mistura pela forma durante a etapa de prensagem.

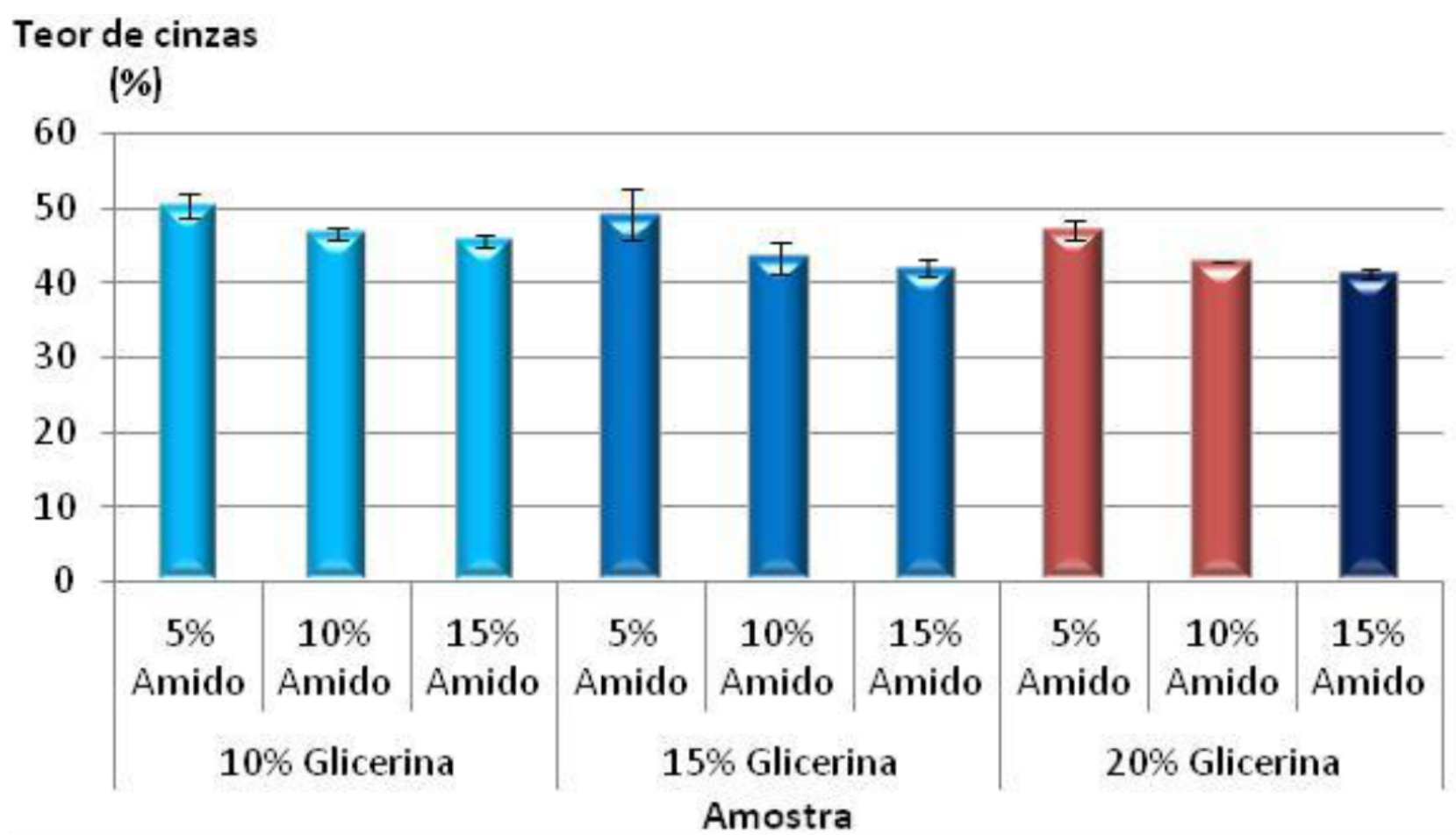

Figura 2: Resultados do teor de cinzas

Todos os briquetes produzidos tiveram os valores de teor de cinzas na faixa de 40 a $50 \%$. Além disso, observa-se uma tendência, à medida que se diminui a composição de carvão vegetal, a porcentagem de teor de cinzas também foi reduzida.

O melhor valor de teor de cinzas encontrado nos briquetes foi de $41,10 \%$, por apresentar menor percentual de materiais que não participaram da combustão. Este valor foi obtido a partir da composição $15 \%$ de amido de milho, $20 \%$ de glicerina e $65 \%$ de carvão. Em contra partida, 0 pior valor obtido foi de 50,33\% a partir da composição de $5 \%$ de amido de milho, $10 \%$ de glicerina e $85 \%$ de carvão. Com isso, observou-se que o teor de cinzas diminuiu à medida que a fração de carvão nos briquetes diminuiu. 
Obernberger e Thek (2004) afirmam que o elevado teor de cinzas (maiores que $37 \%$ ) pode ser uma indicação de contaminação da matéria-prima por materiais como areia, durante o armazenamento e manuseio. Sabendo também que as cinzas vêm de substâncias inorgânicas e inertes que não participaram da combustão, pôde-se constatar a presença de grandes quantidades de contaminantes nas amostras. É bem provável que os contaminantes estão associados ao manejo da carvoaria, onde os finos do carvão são acumulados no solo, promovendo uma situação bastante favorável ao acúmulo de areia e outros detritos. Apesar de sua enorme quantidade, estes detritos passaram despercebidos durante o processo de remoção de materiais estranhos da matéria-prima. Isso ocorreu devido a sua baixa granulometria e coloração uniforme entre os contaminantes e os finos de carvão.

Com intuito de avaliar a energia liberada na queima dos briquetes, estes foram submetidos à análise de poder calorífico - energia liberada para cada unidade de massa, para cada composição percentual de glicerina, amido de milho e finos de carvão.

A Figura 3 relaciona os valores encontrados com as composições de cada briquete. Os pontos em vermelho (amostras A5-G20 e A10-G20) representam as composições em que houve vazamento de mistura pela forma durante a etapa de prensagem.

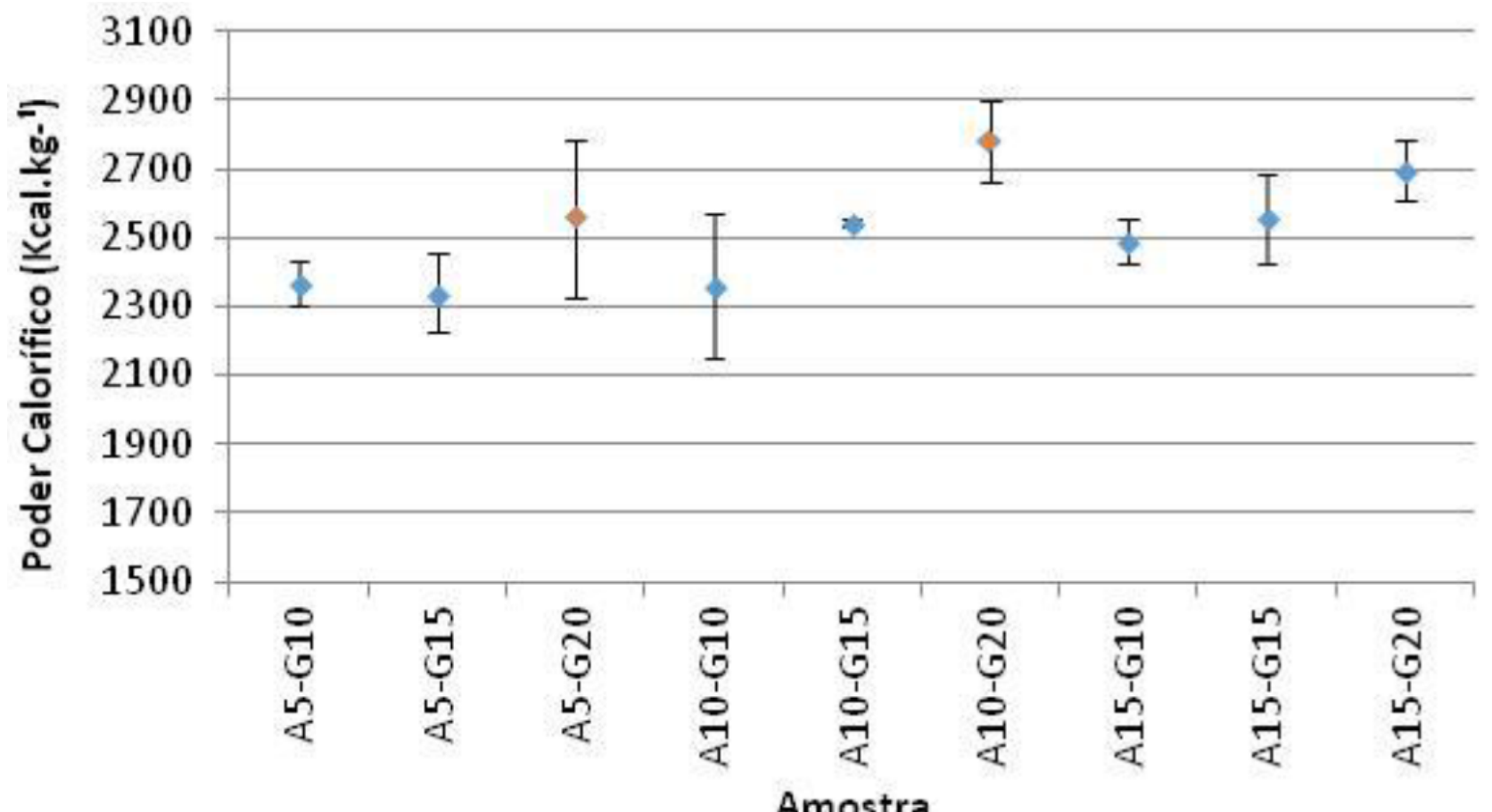

Figura 3: Resultados do poder calorífico

Como visto na Figura 3, há uma tendência de aumento do poder calorífico a medida que aumenta-se a fração de glicerina, deixando claro a influência positiva desta nos briquetes produzidos.

Quanto ao poder calorífico, os valores encontrados nos briquetes variaram entre 2334 e $2781 \mathrm{kcal}^{\mathrm{kg}}{ }^{-1}$, sendo os melhores resultados obtidos a partir dos briquetes que possuíam $20 \%$ de glicerina. Para essa fração de glicerina, os resultados foram: 2781, 2699 e $2558 \mathrm{kcal}^{\mathrm{kg}}{ }^{-1}$. 
Constatou-se, que houve um problema relacionado à contaminação dos finos de carvão por detritos, provavelmente advindos do manejo não controlado do carvão. Essa contaminação afetou negativamente os valores de teor de cinzas e poder calorífico. Com isso, fica clara a importância da implantação de uma etapa mais elaborada de separação para concentrar mais os finos de carvão vegetal, ou então, de uma forma de manejo do carvão que evite submetê-lo a situações passíveis de contaminação.

\section{CONCLUSÃO}

Concluiu-se que é possível confeccionar briquetes através das misturas de carvão vegetal, glicerina e amido de milho em diversas composições. Através dos resultados obtidos nas análises, constatou-se que a variação na composição dos briquetes impacta diretamente em suas características físico-químicas. A produção de briquetes de finos de carvão vegetal e glicerina bruta é tecnicamente viável, proporcionando uma opção de destino para ambos os materiais.

Sugere-se que outras pesquisas possam verificar a produção de briquetes utilizando outros resíduos juntamente com os finos de carvão e a glicerina, assim como verificar a utilização do amido em diferentes proporções, e o uso de outros aglutinantes.

\section{REFERÊNCIAS}

Anger, S., Trimis, D., Stelzner, B., \& Makhynya, Y. (2011). Development of a porous burner unit for glycerine utilization from biodiesel production by Supercritical Water Reforming. International Journal of Hydrogen Energy, 36(13), 7877-7883.

Astals, S., Ariso, M., Galí, A., \& Mata-Alvarez, J. (2011). Co-digestion of pig manure and glycerine: experimental and modelling study. Journal of Environmental Management, 92(4), 1091-1096.

Basquerotto, C. (2010). Cogeração de energia elétrica com bagaço de cana-de-açúcar compressado (briquete). 2010. Monografia (Graduação em Tecnologia em Biocombustíveis). Centro Estadual de Educação Tecnológica Paula Souza, Araçatuba, São Paulo.

Carvalho, E. D., \& Brinck, V. (2004). Briquetagem em Tratamento de Minérios. Luz, A.B.; Sampaio, J.A.; Almeida, S. LM (Eds). Tratamento de Minérios. 4a ed. Rio de Janeiro: CETEM/MCT, 613-635.

Cordoba, M., \& Yeferson, A. (2011). Estudo da combustão direta da glicerina bruta e loira como alternativa de aproveitamento energético sustentável (Doctoral dissertation, Universidade de São Paulo).

Magossi, D. (2007). A produção florestal e a industrialização de seus resíduos na região de Jaguariaíva-Paraná. 2007. 88 f. Dissertação (Mestrado em Engenharia Florestal) -Universidade Federal do Paraná, Curitiba.

Melo, V. D. P. S. D. (1999). Produção de briquetes de carvão vegetal com alcatrão de madeira. Tese de doutorado - Universidade Federal de Viçosa, Viçosa.

Moraes, C. H. (2011). Processo e dispositivos para fabricação de briquetes a partir de finos de carvão vegetal com aglomerante a base de extrato de frutos de palmeiras da espécie syagrus. Patente com registro PI0903475-7A2. Brasil. 
Mota, C. J., Silva, C. D., \& Gonçalves, V. L. (2009). Gliceroquímica: novos produtos e processos a partir da glicerina de produção de biodiesel. Química Nova, 32(3), 639-648.

Obernberger, I., \& Thek, G. (2004). Physical characterisation and chemical composition of densified biomass fuels with regard to their combustion behaviour. Biomass and bioenergy, 27(6), 653-669. Pelissari, D. C.; Amaral, D. F.; Esteves, R. S. (2012). Avaliação da viabilidade técnica da incorporação do lodo primário da indústria de celulose na composição de briquetes. Monografia (Trabalho de conclusão do curso de Engenharia Química) - Faculdades Integradas de Aracruz, Aracruz.

Protásio, T. D. P., Bufalino, L., Mendes, R. F., Ribeiro, M. X., Trugilho, P. F., \& Leite, E. R. D. S. (2012). Torrefação e carbonização de briquetes de resíduos do processamento dos grãos de café. Revista Brasileira de Engenharia Agrícola e Ambiental, Campina Grande, 16(11), 1252-1258. Quirino, W. F., \& Brito, J. O. (1991). Características e índice de combustão de briquetes de carvão vegetal. IBAMA, Laboratório de Produtos Florestais.

Rodrigues, L. D., SILVA, I. T. D., \& ROCHA, B. R. P. D. (2002). Uso de briquetes compostos para produção de energia no Estado do Pará. Procedings of the 4th Encontro de Energia no Meio Rural. Sant'Anna, M. C. S., Lopes, D. F. C., Carvalho, J. B. R., \& da Silva, G. F. (2012). Characterization of briquetes obtained agro-industrial residues. Revista Brasileira de Produtos Agroindustriais, 14(3), 289-294.

Striugas, N., Šlančiauskas, S., Makarevičiene, V., Gumbyte, M., \& Janulis, P. (2008). Processing of the glycerol fraction from biodiesel production plants to provide new fuels for heat generation. energetika, 54(3), 5-12. 